Article

\title{
Spark Plasma Sintering of Cobalt Powders in Conjunction with High Energy Mechanical Treatment and Nanomodification
}

\author{
Van Minh Nguyen ${ }^{1}{ }^{(}$, Rita Khanna ${ }^{2, *}$, Yuri Konyukhov ${ }^{3}$, Tien Hiep Nguyen ${ }^{3}{ }^{\circ}$, \\ Igor Burmistrov ${ }^{4} \mathbb{D}$, Vera Levina ${ }^{3}$, Ilya Golov ${ }^{3}$ and Gopalu Karunakaran ${ }^{5}$ \\ 1 Institute of Research and Development, Duy Tan University, Danang 550000, Vietnam; \\ chinhnhan88@gmail.com \\ 2 School of Materials Science and Engineering (Ret.), University of New South Wales (UNSW), \\ Kensington, Sydney 2052, Australia \\ 3 Department of Functional Nanosystems and High-Temperature Materials, National University of Science \\ and Technology “MISiS”, Moscow 119049, Russia; martensit@mail.ru (Y.K.); htnru7@yandex.ru (T.H.N.); \\ vvlevina@gmail.com (V.L.); gorlym@live.ru (I.G.) \\ 4 Engineering Centre, Plekhanov Russian University of Economics, Moscow 117997, Russia; \\ glas100@yandex.ru \\ 5 Biosensor Research Institute, Department of Fine Chemistry, Seoul National University of Science and \\ Technology (Seoul Tech.), Seoul 232, Korea; karunakarang5@gmail.com \\ * Correspondence: rita.khanna66@gmail.com; Tel.: +82-61-04217-97500
}

Received: 24 April 2020; Accepted: 21 May 2020; Published: 23 May 2020

\begin{abstract}
Spark plasma sintering (SPS) investigations were carried out on three sets of Co specimens: untreated, high energy mechanically (HEMT) pre-treated, and nanomodified powders. The microstructure, density, and mechanical properties of sintered pellets were investigated as a function of various pre-treatments and sintering temperatures $\left(700-1000^{\circ} \mathrm{C}\right)$. Fine-grained sinters were obtained for pre-treated Co powders; nano-additives tended to inhibit grain growth by reinforcing particles at grain boundaries and limiting grain-boundary movement. High degree of compaction was also achieved with relative densities of sintered Co pellets ranging between $95.2 \%$ and $99.6 \%$. A direct co-relation was observed between the mechanical properties and densities of sintered Co pellets. For a comparable sinter quality, sintering temperatures for pre-treated powders were lower by $100{ }^{\circ} \mathrm{C}$ as compared to untreated powders. Highest values of bending strength (1997 MPa), microhardness (305 MPa), and relative density (99.6\%) were observed for nanomodified HEMT and SPS processed Co pellets, sintered at $700{ }^{\circ} \mathrm{C}$.
\end{abstract}

Keywords: spark plasma sintering; nanomodification; mechanical processing; densification; mechanical properties

\section{Introduction}

Spark plasma sintering is finding increasing application as a key technology for hard or very hard to sinter high performance materials [1,2]. The SPS technique has made significant contributions to the development of advanced materials such as refractory materials, functional nano ceramics, non-equilibrium materials, biomaterials, etc. [3]. Based on low voltage, pressure assisted, fast heating with DC pulsed current, the SPS technique has high sintering speed, reproducibility, and reliability with a great potential for achieving fast densification results with minimal grain growth in a short sintering time [4-7]. Depending on the experimental configuration, sample geometry, thermal and electrical characteristics, heating rates as high as $1000{ }^{\circ} \mathrm{C} / \mathrm{min}$ and processing times of few minutes can be 
achieved [4]. A few representative examples of SPS application include: the strengthening of alumina matrix with nanocomposites [8], large sized bulk metallic glasses $[9,10]$, consolidation of metallic powders [11-13], formation of porous materials [14], biomedical applications [15], formation of super alloys [16], carbides [17], orthopedic alloys [18], etc.

During SPS operations, the heating power is distributed homogeneously over the volume of the powder compact on a macroscopic scale. However, microscopically the heating power is dissipated preferentially at the contact points between powder particles [4]. Pulsed current causes surface activation of powders and enhanced diffusion in contact areas. According to the plasma/micro-spark theory, a spark discharge occurring between powder particles creates a local high temperature state leading to vaporization, local surface melting, and the formation of necks/constricted shapes in the contact region [19]. As only the surface temperatures rise sharply through self-heating, the grain growth, coarsening, and particle decomposition of the original particle are inhibited during the SPS process. [20] For example, nanosized particles can be sintered using SPS without considerable grain growth [21]. Such consolidation behavior can also result in completely novel microstructures and materials, thereby opening new areas of research and applications. Due to plastic transformations, high relative densities for powder sinters can be achieved in a short time.

Deng et al. (2019) reported on minor non-thermal effects of electric current such as electromigrationenhanced densification during the SPS process [22]. Lee et al. [2] reported on the densification mechanisms for SPS consolidation of tungsten powders; the sintering was carried in the temperature range $1600-1800{ }^{\circ} \mathrm{C}$ (melting point of $\mathrm{W}: 3422^{\circ} \mathrm{C}$ ) and pressures of 60 and $120 \mathrm{MPa}$. The relative density of the compacted pellets was found to range between $81-95 \%$; there was some evidence for superplastic-like behavior based on electron back-scattering results. Knaislová et al. [23] carried out high pressure SPS sintering of Ti-Al-Si intermetallic alloys at pressures of $6 \mathrm{GPa}$ and temperatures ranging from 1045 to $1324{ }^{\circ} \mathrm{C}$ to produce low-porosity consolidated specimens of $\mathrm{Ti}_{5} \mathrm{Si}_{3}$ silicides in an TiAl matrix. Marek et al. (2016) reported on the synthesis of ultrafine and microcrystalline cobalt using high-energy ball milling followed by the SPS process; relative densities of $88.8 \%$ to $97.8 \%$ were achieved [24]. Kundu et al. (2019) used high energy ball milling on Fe-9Cr alloys followed by SPS consolidation for a range of dwell times $(7-45 \mathrm{~min})$ and temperatures $\left(850-1050{ }^{\circ} \mathrm{C}\right)$ to achieve a maximum relative density of $98 \%$ [25].

The aim of this study is to enhance the efficacy of the SPS process with appropriate pre-treatments, and to investigate the densification, mechanical and microstructural properties of sintered cobalt pellets. Due to high corrosion resistance, excellent mechanical properties, biocompatibility, cobalt-based alloys are used in the manufacture of combustion chambers in gas turbines [26], strengthened superalloys [27], biomedical and orthopedic applications, surgical implants, etc. [28,29]. Using high-energy mechanical treatment and nanomodification in conjunction with the SPS process, in-depth investigations were carried out on three sets of specimens over a range of temperatures. The influence of various operating conditions on density, microstructure, and mechanical properties of sintered Co pellets was investigated towards process optimization, and to produce high-quality sintered materials at lower sintering temperatures.

The article is organized as follows. Details on the synthesis of cobalt nanopowders, operational details of high energy mechanically and SPS treatments are presented in Section 2 (Materials and Methods), along with a detailed experimental plan. Results on density measurements, microstructure, bending strength, microhardness, and carbon diffusion on the reacted surface are presented in Section 3 (Results and Discussion), followed by critical analysis and discussion. Key findings from the study and conclusions are summarized in Section 4 (Conclusions).

\section{Materials and Methods}

There were three key experimental procedures in this study: synthesis of Co nanopowders, high energy mechanical treatment, and spark plasma sintering. Operational features of these procedures and experimental plan are detailed below. 


\subsection{Synthesis of Co Nanopowders}

Co micropowder (Brand: PK-lu-electrolytic, NPO Rusredmet, St. Petersburg, Russia) was used as the starting material for this investigation. Basic characteristics of Co powder were determined as: purity $\geq 99.35 \%$; Brunauer-Emmet-Teller (BET) surface area: $0.2 \mathrm{~m}^{2} / \mathrm{g}$; average particle size: $3.4 \mu \mathrm{m}$. Chemical precipitation was used to synthesize nanoparticles using the precipitation of $\mathrm{Co}(\mathrm{OH})_{2}$ from $10 \% \mathrm{Co}\left(\mathrm{NO}_{3}\right)_{2} ; 10 \% \mathrm{NaOH}$ solution was added to catalyze precipitation. This reaction was followed by thermal reduction at $265^{\circ} \mathrm{C}$ for $3 \mathrm{~h}$ under $\mathrm{H}_{2}$ flow, and the resulting nanopowders were passivated at liquid nitrogen temperatures. The presence of a small amount of oxygen in the commercial grade technical $\mathrm{N}_{2}(<0.4 \%$ oxygen) can lead to the formation of a thin (up to $5 \mathrm{~nm}$ ) oxide surface layer on nanoparticles. Therefore, these nanopowders could contain up to $3 \mathrm{wt}$. \% of oxygen. Synthesized Co nanoparticles were characterized using advanced analytical techniques: Scanning electron microscopy (Tescan Vega 3, TESCAN, Brno, Czech Republic); transmission electron microscopy (JEM-2010, JEOL, Tokyo, Japan); X-ray diffraction (Difrey 401, Scientific Instruments, Russia), BET surface area measurement (NOVA 1200, Quantachrome Instruments, Boynton Beach, Florida, USA). Detailed characterization results are presented next.

Figure $1 \mathrm{~A}$ shows $\mathrm{X}$-ray diffraction results $(\mathrm{Cu} \mathrm{K} \alpha ; 40 \mathrm{kV} ; 40 \mathrm{~mA})$ for synthesized Co nanopowders. Most of the diffraction peaks (shown in 'black') corresponded to the hcp phase of Co. The observed peak height of the $(101)$ peak $\left(100 \% ; 47.39^{\circ}\right)$ was much smaller than the $(002)$ peak $\left(28.6 \% ; 44.26^{\circ}\right)$. The (101) peak was also found to be relatively broad, whereas (002) peak was quite sharp and narrow. These results indicate the presence of texture in these nanopowders. A small amount of the fcc phase was also detected with two weak peaks (shown in 'red') at $45.922^{\circ}((111) ; 100 \%)$ and $53.456^{\circ}((002)$; $41.9 \%$ ). Figure 1B shows a selected area electron diffraction patten (SAED) on cobalt nanoparticles during transmission electron microscopy (TEM) investigations. The presence of sharp diffraction spots indicates the crystalline nature of these particles. This result is in good agreement with X-ray diffraction results (Figure 1A).

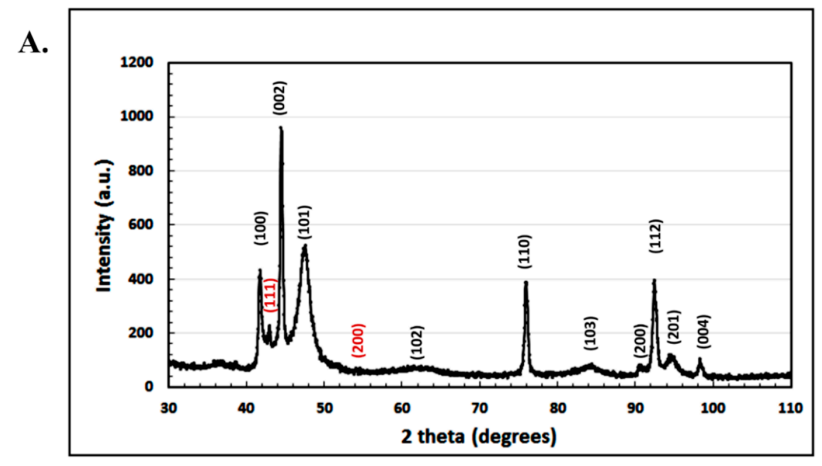

B.

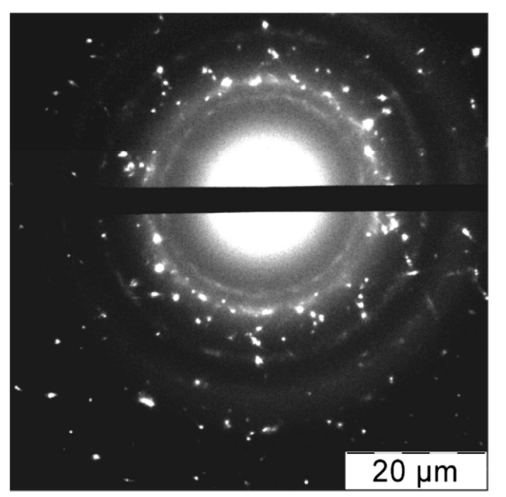

Figure 1. (A) X-ray diffraction $(\mathrm{Cu} \mathrm{K} \alpha)$, and (B) selected area electron diffraction (SAED) results on synthesized Co nanopowders. 
Figure 2a-d shows electron microscopy images (both SEM and TEM) of synthesized Co nanoparticles in a range of magnifications. While most of the particles were well rounded, their shapes were generally irregular with no well-defined form or shape. There was no specific tendency towards spherical morphologies. These nanoparticles tended to reduce their surface area by agglomerating into clumps larger than 150-200 nm (Figure 2a-d). From BET surface area measurements, the specific surface area of synthesized Co nanoparticles was determined to be $10.1 \mathrm{~m}^{2} / \mathrm{g}$. The average particle size was found to be $67 \mathrm{~nm}$. The presence of agglomerates imposes certain requirements for their introduction into polydisperse media. Additional energy needs to be supplied to the system to break up these aggregates and to achieve a high degree of homogenization of the mixture during the nanoparticle injection process.
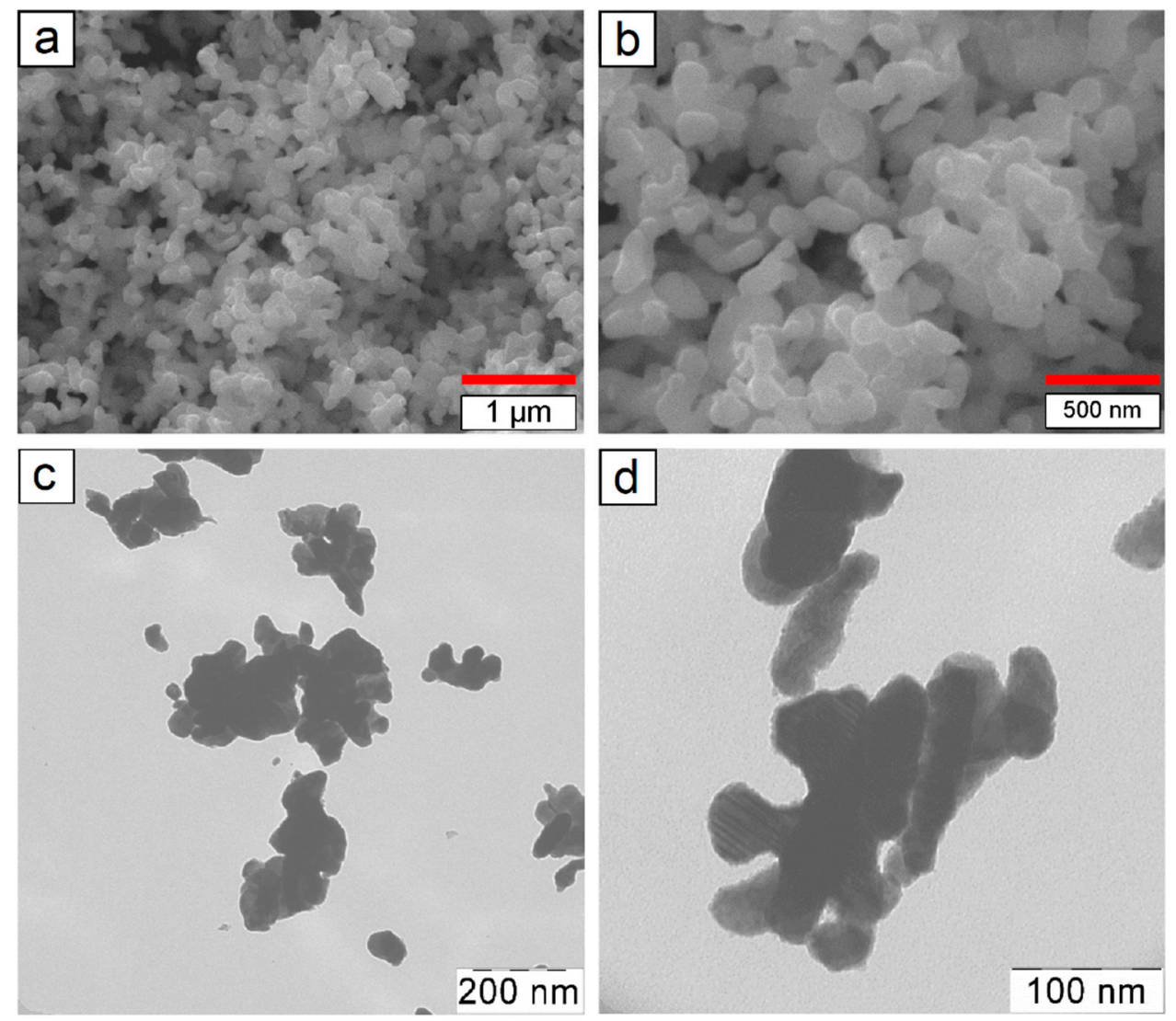

Figure 2. (a,b) SEM and (c,d) TEM micrographs of synthesized Co nanopowders.

\subsection{High Energy Mechanical Treatment}

A magnetic mill (UAP-3, 21st Century Advanced Technology, Russia) was used to carry out HEMT on Co powders under argon atmosphere. Key components of the equipment include a magnetic inductor to generate a high-power vortex magnetic field, water cooling circuit, electric resistance tube furnace, and a steel reaction chamber ( $45 \mathrm{~mm}$ dia., $350 \mathrm{~mm}$ length). Further details have been given elsewhere [30]. The simultaneous influence of high-power vortex magnetic field (0.16 T) and mechanical processing of sample powders with ferromagnetic stainless steel needles in the reaction chamber creates intense vortex rotation with speeds reaching $3200 \mathrm{rpm}$. Pressures within the chamber can build up to several thousand MPa during operation. In this study, hard-wearing steel needles of length 15-20 mm, 0.6-1.2 mm dia. were used as the ferromagnetic bodies to form the vortex layer. The relative proportion of ferromagnetic needles to Co powder in the reaction chamber was chosen to be $4: 1$ by weight. Co nanoparticles $(0.5 \mathrm{wt}$. \%) were first mixed with Co micro-powders in air. 
The HEMT treatment was carried out on the mixture in an argon atmosphere. Steel needles were separated from the processed material by a sieve. A processing time of 3 min was used for all powders.

During the HEMT operation, sample powders get mixed extensively in the reaction chamber and may undergo deformations along with changes in structure and reactivity [30,31]. Figure 3 shows the morphology of Co particles before and after HEMT. Co particles were almost spherical initially (Figure 3a). One minute of HEMT processing shows surface deformation and elongation of some particles; not all particles were equally affected (Figure 3b). However, 2 min of HEMT processing showed a significant flattening, increases in particle sizes, and transformation from spherical to disc shapes (Figure 3c). Such changes in morphology can play a significant role in increasing contact regions between Co particles during sintering.

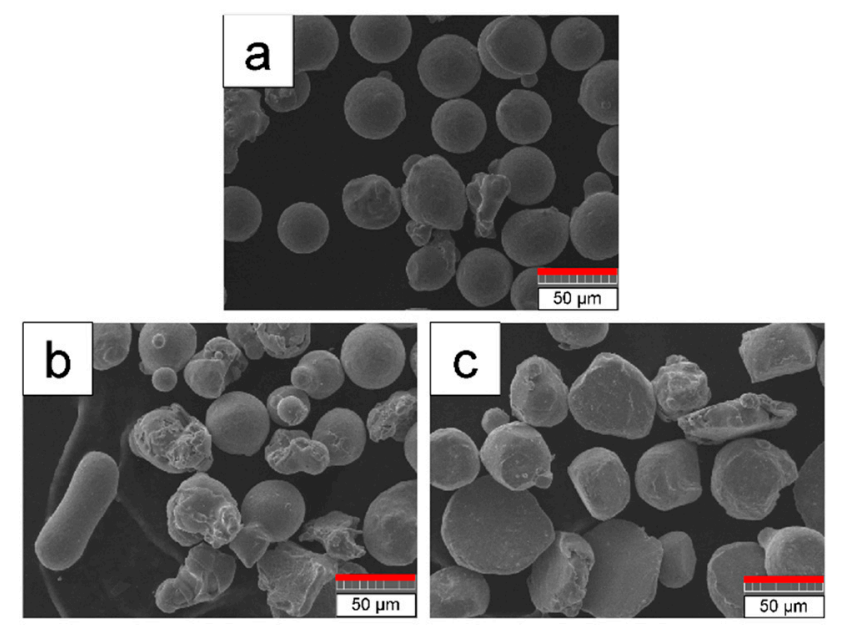

Figure 3. SEM images of Co powders after HEMT operation. (a) $t=0 \mathrm{~min},(\mathbf{b}) t=1 \mathrm{~min},(\mathbf{c}) t=2 \mathrm{~min}$.

\subsection{Spark Plasma Sintering}

Commercial SPS equipment LABOX-650 (Sinter Land Inc., Kyoto, Japan) was used in this investigation. Key operating parameters were temperature: $\leq 2400{ }^{\circ} \mathrm{C}$; pressing force: $0.5-60 \mathrm{kN}$; heating rates: $\leq 500{ }^{\circ} \mathrm{C} / \mathrm{min}$; operating current: $\leq 5000 \mathrm{~A}$; cylinder stroke $150 \mathrm{~mm}$; sintering under vacuum or inert atmosphere. Approximately $27 \mathrm{~g}$ of cobalt powder was loaded into each matrix with an internal diameter of $3 \mathrm{~cm}$. The inside of matrix was covered by graphite sheets to facilitate the removal of the sintered product. Sintering of powders was carried out under pressure and high temperature spark plasma, generated as an electric discharge between the particles under the influence of a powerful pulsed current. Operating parameters during sintering were pressure $50 \mathrm{MPa}$, heating rate $50^{\circ} \mathrm{C} / \mathrm{min}$, holding time $5 \mathrm{~min}$, temperatures ranging from 700 to $1000^{\circ} \mathrm{C}$. A pulsed direct current (500-2500 A) was passed through the sample and the mold; the temperature was measured with help of a thermocouple and a pyrometer. The voltage and current were changed automatically to provide the preset heating and holding modes. Sintered samples were cooled to room temperature. The average height of sintered cobalt pellets was found to be $4.2 \pm 0.1 \mathrm{~mm}$.

\subsection{Experimental Plan}

An outline of the experimental plan is shown in Figure 4. Spark plasma sintering was carried out on three sets of specimens: (a) un-treated Co micro-powders, (b) HEMT processed Co powders, and (c) nanomodified ( $0.5 \mathrm{wt}$. \% Co nanopowders additive) Co micro-powders subjected to HEMT processing. The concentration of nanopowders in the blend was determined by technological and economic considerations [32-35]. Detailed structure-property measurements including density, microstructure, microhardness, and bending strengths were determined for Co pellets sintered for a range of temperatures. 


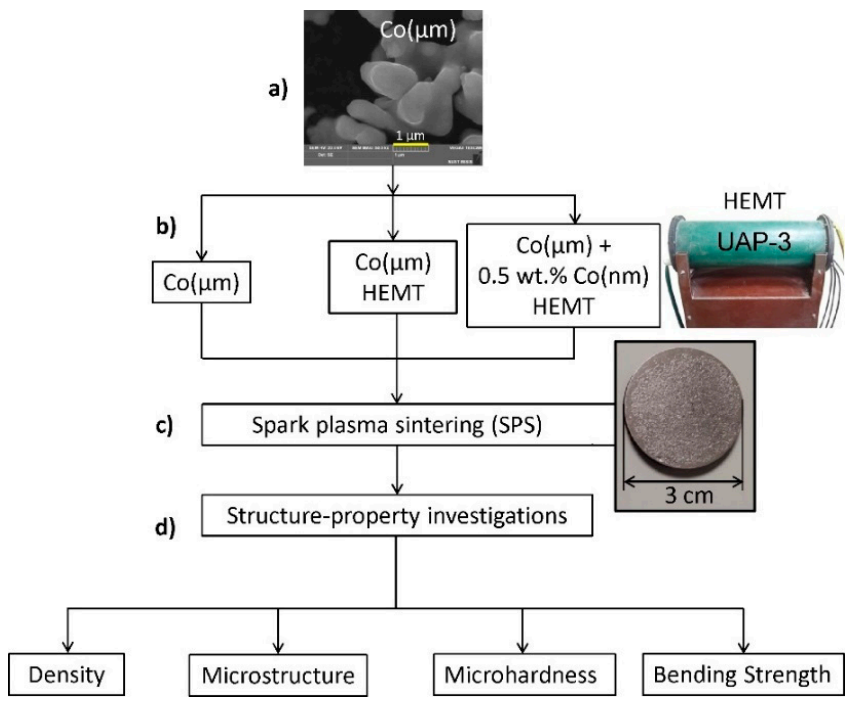

Figure 4. An overview of the experimental plan.

\section{Results and Discussion}

The SPS consolidation was carried out on three sets of Co powders over a range of temperatures. Detailed results on sintered pellets are presented next. These are followed by critical analysis and discussion.

\subsection{Morphology and Microstructure}

High resolution micrographs depicting the morphologies of Co powders following HEMT and nanomodification pre-treatments are shown in Figure 5. Figure 5a (set I) shows that untreated, as received Co particles were well rounded with sizes generally around $3 \mu \mathrm{m}$, which is consistent with BET results on starting Co powders. The HEMT processing (Figure 5b, set II) led to the crushing, milling, surface roughening, and size reduction of Co microparticles producing irregular shaped particles in a range of sizes. Figure 5c (set III) shows the effect of HEMT processing on nanomodified Co powders. Nanoparticles were seen evenly distributed throughout the powder mixture and showed a tendency to attach with bigger microparticles. The HEMT pre-treatment was seen to cause a high degree of deformation, mixing, homogenization, and activation of Co powders prior to SPS consolidation.
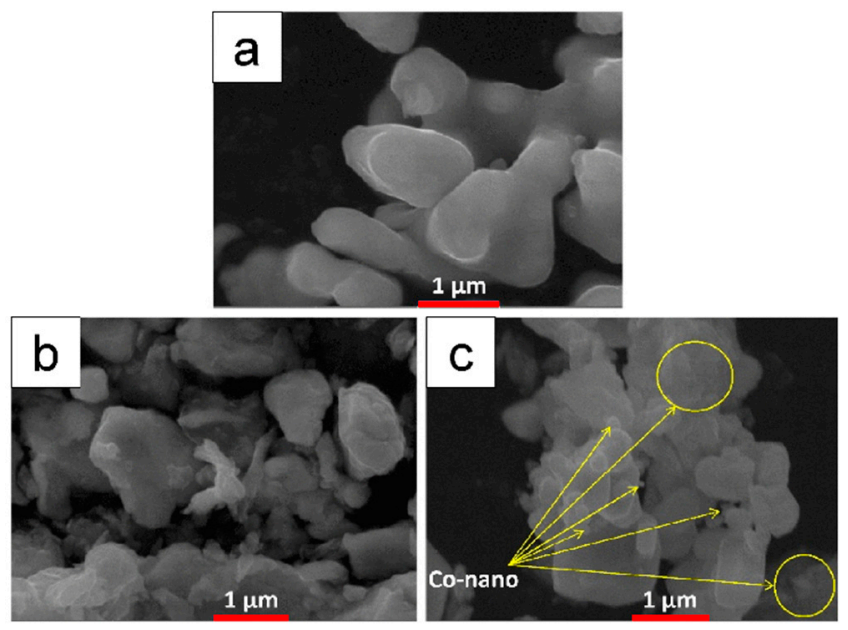

Figure 5. The SEM micrographs of three sets of Co micropowders: (a) untreated Co powder, (b) HEMT treated Co powder, (c) nanomodification, and HEMT treatments on Co powders. 
Figure 6 shows optical micrographs (Axio Observer D1m; Carl Zeiss, Oberkochen, Germany) on the microstructure of Co pellets sintered at $700{ }^{\circ} \mathrm{C}$. Samples were polished to a mirror finish and were etched with $30 \mathrm{wt}$ \% nitric acid for $5 \mathrm{~s}$. The largest grain size was observed in Figure 6a (set I) for Co powders without any pre-treatment. Figure $6 \mathrm{~b}, \mathrm{c}$ (sets II and III) show that the grain-size had decreased significantly for HEMT processed and nanomodified and HEMT treated Co powders. The largest number of grains were observed for set III.

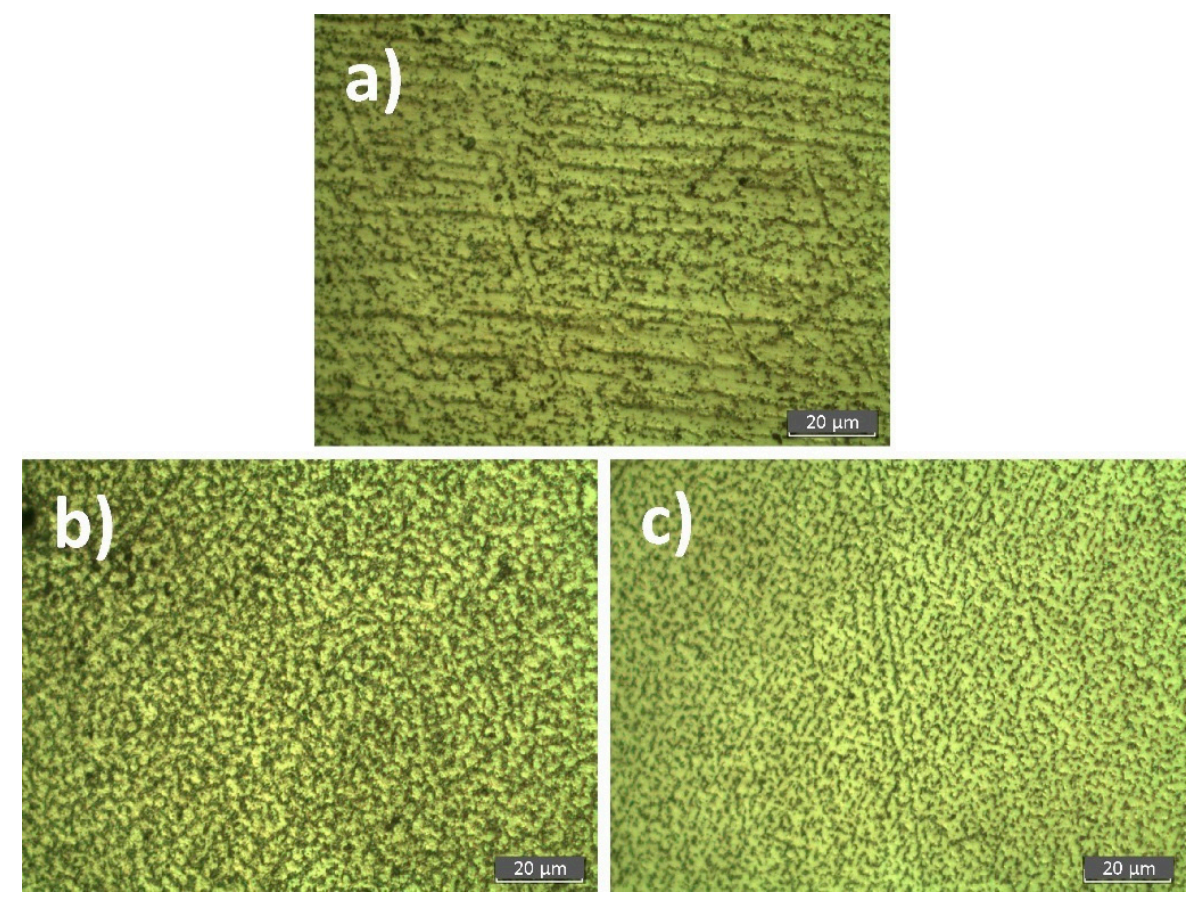

Figure 6. Microstructure of sintered Co pellets $\left(700^{\circ} \mathrm{C}\right)$ for sets (a) I, (b) II, (c) III of Co powders as determined through optical microscopy.

\subsection{Densification}

The densities of sintered samples were determined using gas pycnometry technique (Ultra pycnometer 1000, Quantachrome Instruments, Boynton Beach, Florida, USA). These measurements were made with an accuracy of $\pm 0.03 \%$. Detailed results are shown in Figure 7 . Figure $7 \mathrm{~A}$ shows the impact of sintering temperatures on the three sets of specimens. Densities of sintered Co pellets were found to range between 8473 to $8860 \mathrm{Kg} / \mathrm{m}^{3}$ (theoretical density: $8890 \mathrm{Kg} / \mathrm{m}^{3}$ ). Corresponding relative densities have been plotted in Figure 7B. These were found to range between $95.2 \%$ to $99.6 \%$, indicating extensive densification under certain operating conditions.

For the set I representing SPS consolidation on as received Co micro-powders, the density of sintered pellets increased from $8585 \mathrm{Kg} / \mathrm{m}^{3}\left(700{ }^{\circ} \mathrm{C}\right)$ to $8840 \mathrm{Kg} / \mathrm{m}^{3}\left(800{ }^{\circ} \mathrm{C}\right)$ and later decreased with increasing temperatures reaching magnitudes of $8528 \mathrm{Kg} / \mathrm{m}^{3}\left(900{ }^{\circ} \mathrm{C}\right)$ and $8604 \mathrm{Kg} / \mathrm{m}^{3}\left(1000{ }^{\circ} \mathrm{C}\right)$. Maximum relative density of $99.3 \%$ was achieved at $800^{\circ} \mathrm{C}$. For the set II representing SPS results on Co micro-powders with HEMT pre-treatment, highest pellet density $\left(8847 \mathrm{Kg} / \mathrm{m}^{3}\right)$ was achieved at $700{ }^{\circ} \mathrm{C}$. Higher processing temperatures showed lower densities: $8660 \mathrm{Kg} / \mathrm{m}^{3}\left(800{ }^{\circ} \mathrm{C}\right), 8473 \mathrm{Kg} / \mathrm{m}^{3}$ $\left(900{ }^{\circ} \mathrm{C}\right), 8615 \mathrm{Kg} / \mathrm{m}^{3}\left(1000^{\circ} \mathrm{C}\right)$. Results for the set III, representing SPS results on nanomodified Co micro-powders with HEMT pre-treatment, followed a trend similar to the set II. However, overall densities were slightly higher in set III as compared to set II. Highest pellet density $\left(8860 \mathrm{Kg} / \mathrm{m}^{3}\right) \mathrm{was}$ achieved at $700{ }^{\circ} \mathrm{C}$. Higher processing temperatures generally showed lower densities: $8740 \mathrm{Kg} / \mathrm{m}^{3}$ $\left(800^{\circ} \mathrm{C}\right), 8556 \mathrm{Kg} / \mathrm{m}^{3}\left(900{ }^{\circ} \mathrm{C}\right), 8689 \mathrm{Kg} / \mathrm{m}^{3}\left(1000^{\circ} \mathrm{C}\right)$. 
A.

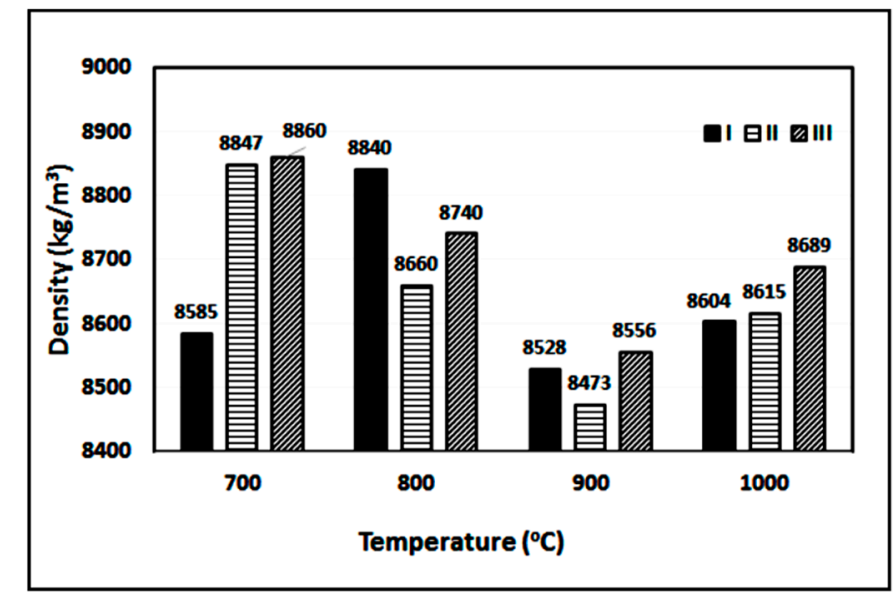

B.

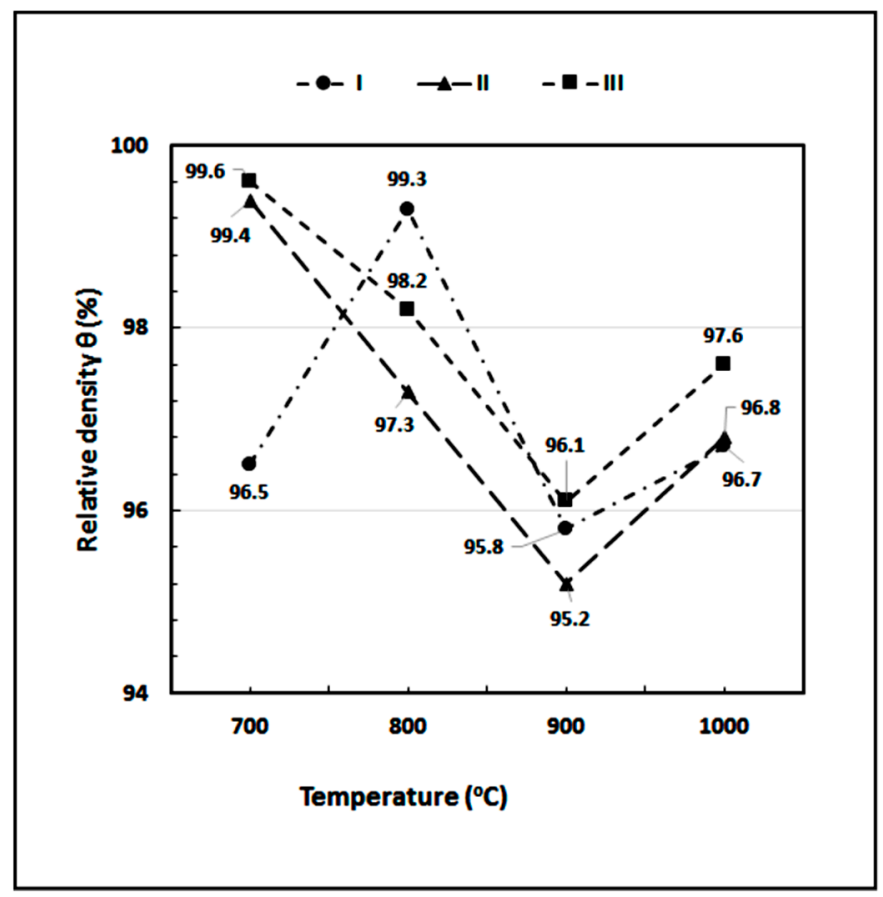

Figure 7. Influence of sintering temperature on (A) absolute densities and (B) relative densities of three sets of Co powders.

\subsection{Mechanical Properties}

The mechanical properties of sintered samples such as microhardness and bending strength were determined using the microhardness tester (Tukon TM 1102, Wilson hardness, Norwood, MA, USA) and universal testing machine (Instron 5966, Instron, Norwood, MA, USA), respectively. The impact of pre-treatments and sintering temperatures on the bending strength of sintered pellets is shown in Figure 8a. At $700{ }^{\circ} \mathrm{C}$, the bending strength was lowest for untreated Co powders (set I: $1639 \mathrm{MPa}$ ). With HEMT pre-treatment and nanomodification, increases to $1878 \mathrm{MPa}$ (set II) and $1997 \mathrm{MPa}$ (set III) were recorded. This trend was reversed at $800{ }^{\circ} \mathrm{C}$, albeit with lower bending strengths, with highest value recorded for set I (1781 MPa); sets II and III recorded 1679 and $1728 \mathrm{MPa}$, respectively. All three sets showed similar bending strengths at $900{ }^{\circ} \mathrm{C}$. Bending strengths showed a small increase at $1000^{\circ} \mathrm{C}$ with trends between various sets similar to those observed at $700{ }^{\circ} \mathrm{C}$. Bending strengths of sintered Co pellets were strongly affected by the initial pre-treatments and temperatures of SPS consolidation. Maximum bending strength of $1997 \mathrm{MPa}$ was recorded for set III pellets sintered at $700{ }^{\circ} \mathrm{C}$. 
The impact of pre-treatments and sintering temperatures on the microhardness of sintered Co pellets is shown in Figure 8b. The microhardness of sintered Co pellets was determined using Vickers scale with a load of $0.3 \mathrm{kgf}$. There appears to be a direct correspondence between the bending strength and microhardness results. At $700{ }^{\circ} \mathrm{C}$, the microhardness was lowest for untreated Co powders (set I: $271 \mathrm{MPa}$ ). With HEMT pre-treatment and nanomodification, increases to $298 \mathrm{MPa}$ (set II) and $305 \mathrm{MPa}$ (set III) were recorded. All three sets showed similar microhardness values at $800{ }^{\circ} \mathrm{C}$; while set I showed a marginal increase, small reductions were observed for both sets II and III. Further reductions were observed at $900{ }^{\circ} \mathrm{C}$, followed by a small increase at $1000{ }^{\circ} \mathrm{C}$. Following a trend similar to bending strength, microhardness of sintered Co pellets showed a strong dependence on initial pre-treatments and temperatures of SPS consolidation. Highest values of microhardness were observed for nanomodified HEMT and SPS processed samples (set III). Maximum hardness of $305 \mathrm{MPa}$ was recorded for set III at $700{ }^{\circ} \mathrm{C}$.
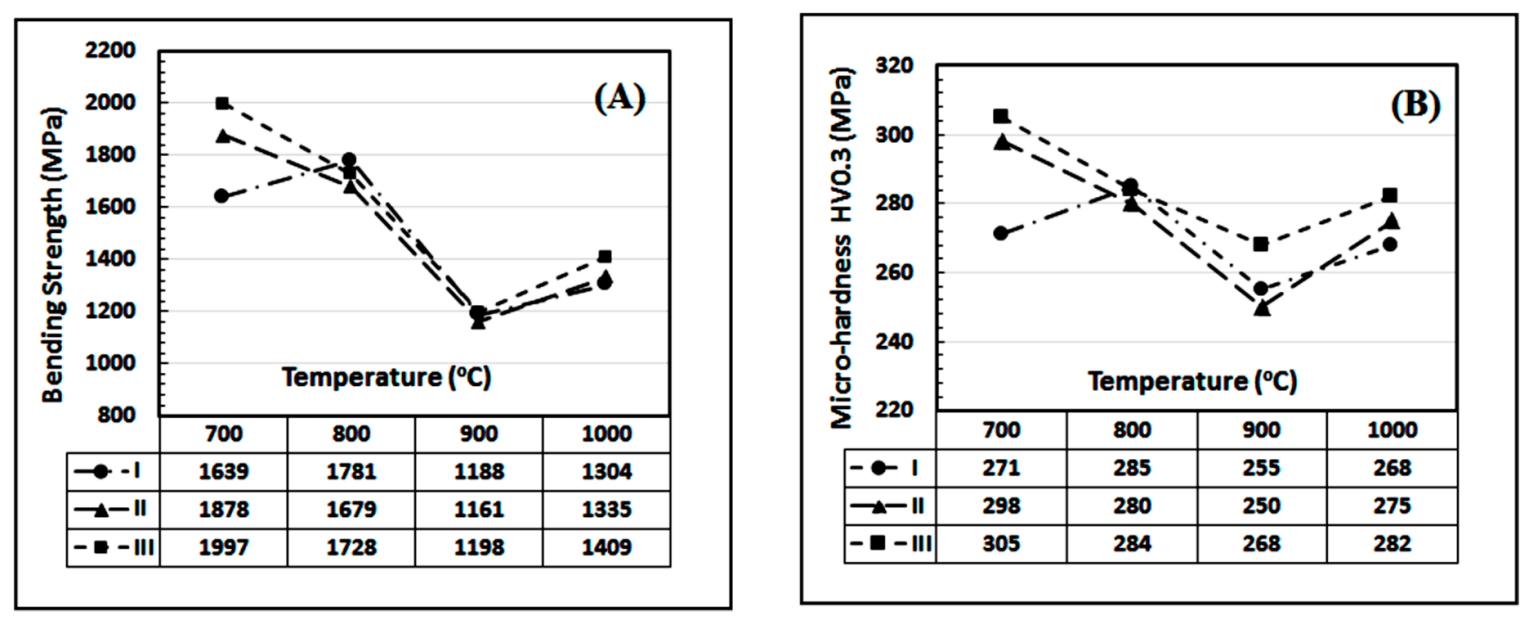

Figure 8. Impact of pre-treatments and sintering temperatures on (A) bending strength and (B) microhardness of sintered pellets.

During SPS sintering, graphite inlays in the sintering matrix can be a source of carbon diffusion into the Co pellet and may form a thin surface layer of carbide [36]. This can seriously impact the mechanical properties of the sintered pellet. To estimate the extent of carbon penetration, microhardness of the sintered pellet (set III, $1000{ }^{\circ} \mathrm{C}$ ) was determined as a function of distance from the surface (Figure 9). Carbon penetration depth was estimated to be $\sim 0.3 \mathrm{~mm}$ as indicated by the regions of low microhardness.

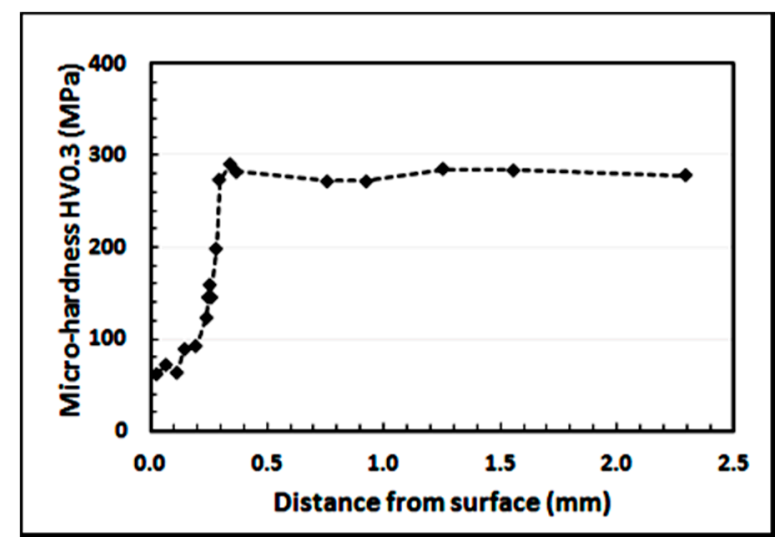

Figure 9. Impact of surface carbon diffusion on the microhardness of sintered Co pellets (set III, $\left.1000^{\circ} \mathrm{C}\right)$. 


\subsection{Discussion}

This study was focused on the roles of initial pre-treatments including high energy mechanical treatment and nanomodification, and SPS consolidation temperatures on the basic characteristics of sintered Co pellets. Initial pre-treatments had a strong influence on the morphology of Co powders prior to sintering. While untreated Co powders (set I) were well rounded, high energy mechanical treatment (set II) caused major particle deformations, disintegrations, and the generation of odd shaped particles in a range of sizes. The addition of $0.5 \mathrm{wt}$. \% Co nanopowders (set III) provided fillers for closing small gaps during sintering. These treatments had a strong influence on the grain sizes of the sintered pellets. The operating temperatures of SPS consolidation $\left(700-1000{ }^{\circ} \mathrm{C}\right)$ were significantly lower than the melting point of cobalt $\left(1495^{\circ} \mathrm{C}\right)$. As very limited grain growth is expected during low temperature SPS sintering, the large grain size of sintered Co pellets (set I; $700{ }^{\circ} \mathrm{C}$ ) is consistent with large particle sizes of as received Co powders (Figures $3 \mathrm{a}$ and $5 \mathrm{a}$ ). Intensive crushing and associated deformations during HEMT (set II) and the additional presence of nano-modifiers (set III) resulted in a high degree of compaction, filling of gaps, and enhanced sintering. As sintering was carried out at fairly low temperatures, grain growth was strongly inhibited. Fine grain structure was observed for both sets II and III (Figure $6 \mathrm{~b}, \mathrm{c} ; 700^{\circ} \mathrm{C}$ ).

This study showed very high degree of compactions reaching up to $99.6 \%$ relative densities in sintered Co pellets. This was achieved for set III pellets at $700{ }^{\circ} \mathrm{C}, 50 \mathrm{MPa}$ pressure, $50^{\circ} \mathrm{C} / \mathrm{min}$ heating rate, and 5 min of holding time. Results on untreated Co powders (set I) show that highest relative density of $99.3 \%$ was achieved at $800{ }^{\circ} \mathrm{C}$. Fellah et al. [37] achieved maximum relative density $(94.5 \%)$ for cobalt nanopowders with SPS technique at $500{ }^{\circ} \mathrm{C}, 50 \mathrm{MPa}$ pressure, $100{ }^{\circ} \mathrm{C} / \mathrm{min}$ heating rate. Cabibbo (2018) used ball milling and SPS sintering on $2 \mu \mathrm{m}$ cobalt powders to achieve a maximum relative density of $95.8 \%$ [38]. Lee et al. [2] achieved a relative density of $81-95 \%$ for tungsten powders with SPS technique at $1600-1800^{\circ} \mathrm{C}, 60-120 \mathrm{MPa}$ pressure, $100^{\circ} \mathrm{C} / \mathrm{min}$ heating rate, holding times up to $60 \mathrm{~min}$.

Highest relative density of $99.4 \%$ for set II with HEMT pre-treatment was observed at $700{ }^{\circ} \mathrm{C}$, a reduction of sintering temperature by $100^{\circ} \mathrm{C}$ as compared to set I. This result clearly shows that HEMT processing could be used to lower SPS temperature without compromising sinter quality. Other authors have used high energy ball milling as a pre-treatment prior to SPS processing. Marek et al. [24] could achieve relative densities of $88.8-97.8 \%$ on Co powders; and Kundu et al. [25] achieved a maximum relative density of $98 \%$ for Fe-9Cr alloys. Even better results were observed for set III involving both HEMT and nanomodification reaching the highest compaction of $99.6 \%$ at $700{ }^{\circ} \mathrm{C}$. The addition of nano-additives is known to inhibit grain growth by reinforcing particles at grain boundaries and limiting grain-boundary movement $[39,40]$. Reduced porosity, fine grain structure, and a high degree of compaction can also lead to improved mechanical properties of the sintered product.

The temperature of SPS consolidation was found to have a strong influence of densities, bending strength, and microhardness of sintered pellets. Highest degree of compaction (99.6\%), highest bending strength (1997 MPa), highest microhardness (305 MPa) were observed for nanomodified, HEMT processed Co powders sintered at $700{ }^{\circ} \mathrm{C}$. This temperature is even lower than the half melting temperature of $\mathrm{Co}$. A direct correlation was observed between these basic characteristics and the sintering temperature. With temperature increasing from $700^{\circ} \mathrm{C}$, the magnitudes of densities, bending strength, and microhardness of sintered pellets were found to decrease, reaching a minimum at $900^{\circ} \mathrm{C}$ and then starting to increase at $1000^{\circ} \mathrm{C}$. This basic trend was observed for all three sets of Co specimens to a certain degree. This trend cannot be explained in terms of initial particle shapes, morphology, and grain sizes, which were significantly different for the three sets of Co specimens (Figures 5 and 6).

During SPS sintering of Ti- 4.8 wt. \% $\mathrm{TiB}_{2}$ composites, Namini et al. [41] observed a linear increase in relative density from $93.90 \%$ to $99.88 \%$, with sintering temperature increasing from 750 to $1200{ }^{\circ} \mathrm{C}$, thereby indicating high rates of porosity removal. However, the relative density of composites showed a small reduction at $1350^{\circ} \mathrm{C}$ which was attributed to the softening of the matrix at higher temperatures, the grain growth surpassing densification postponing the porosity removal. 
Figure 10 shows the dependence of bending strength and microhardness on the relative densities of sintered pellets. Data was taken from three sets of cobalt samples sintered at 700, 800, 900, and $1000{ }^{\circ} \mathrm{C}$. Both mechanical properties were found to increase linearly with increasing densities. A linear correlation was also observed between the bending strength and microhardness of sintered pellets. These results indicate a direct link between the sinter density and mechanical properties irrespective of the sintering temperature. The impact of SPS temperature on densification and mechanical properties needs to be understood clearly. High resolution microscopic investigations with much smaller temperature steps will be required for creating an extensive database towards developing a fundamental understanding, associated mechanisms, and for optimizing the overall process.

A.

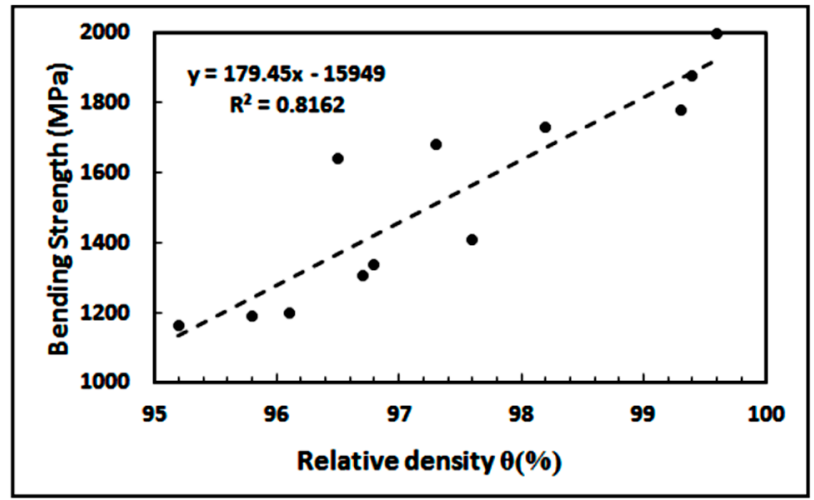

B.

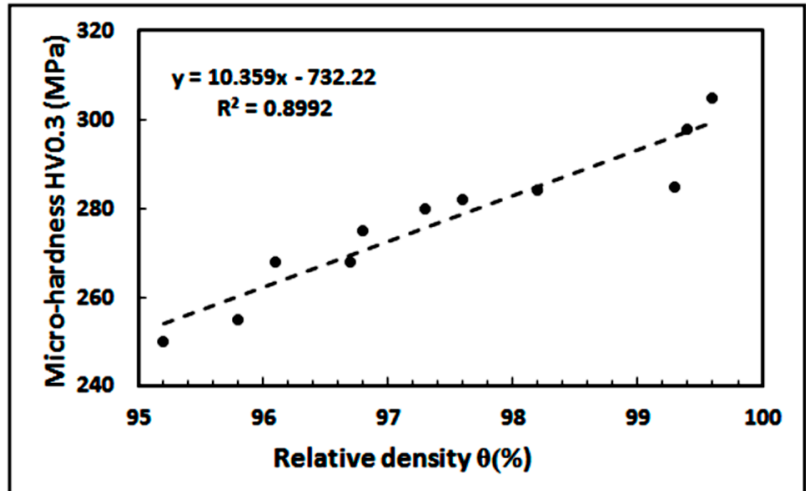

c.

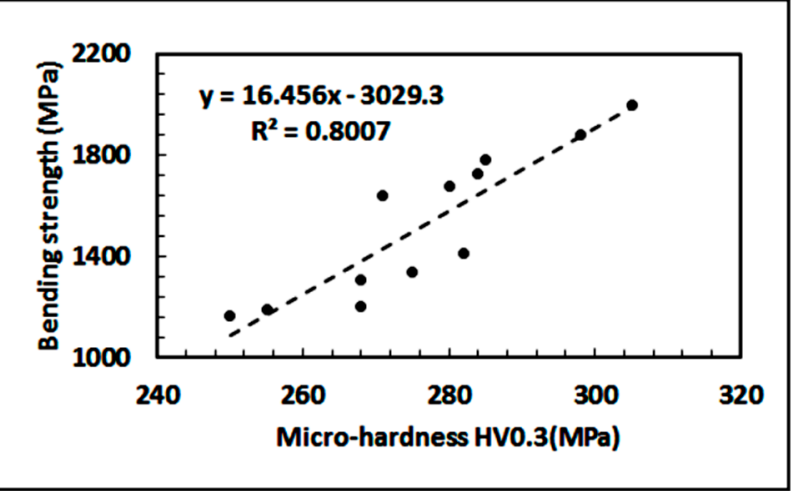

Figure 10. (A-C) Linear dependence of bending strength and microhardness on the relative density of sintered pellets.

\section{Conclusions}

Our results show that HEMT and nanomodification could be used to lower sintering temperatures while providing excellent results on basic characteristics of sintered products. Key findings of this study are: 
(1). Three sets of Co micro-powders were investigated in this study: untreated, HEMT processed, and nanomodified HEMT processed powders. The SPS consolidation was carried out in the temperature range $700-1000{ }^{\circ} \mathrm{C}$.

(2). The grain sizes of sintered Co pellets were largest for set I without any pre-treatment. Fine-grained products were obtained for Co powders undergoing HEMT processing and nanomodification. Nano-additives tended to inhibit grain growth by reinforcing particles at grain boundaries and limiting grain-boundary movement.

(3). Very high degrees of compaction were achieved with relative densities of sintered Co pellets, ranging from $95.2 \%$ to $99.6 \%$. Pre-treatments as well as lower sintering temperatures were found to play a key role in enhancing the sinter quality. A reduction of sintering temperature by $100{ }^{\circ} \mathrm{C}$ was observed for pre-treated Co powders as compared to untreated Co powders for a comparable sinter quality.

(4). Direct and linear co-relations were observed between the mechanical properties and densities of sintered Co pellets. Highest values of bending strength (1997 MPa), microhardness (305 MPa), and relative density $(99.6 \%)$ were observed for nanomodified HEMT and SPS processed Co pellets sintered at $700{ }^{\circ} \mathrm{C}$.

(5). Lowest values of bending strength (1198 MPa), microhardness (268 MPa), and relative density (96.1\%) were observed for nanomodified HEMT and SPS processed Co pellets sintered at $900{ }^{\circ} \mathrm{C}$.

(6). This study has shown that SPS operating temperatures need to be carefully optimized to prevent inadequate sintering at low temperatures and increased porosity, defect formation, and product degradation at high temperatures.

Author Contributions: Conceptualization, V.M.N., Y.K., G.K.; Methodology, V.M.N., T.H.N., Y.K.; Investigation, V.M.N., I.B., V.L., R.K., Writing and Editing, Y.K., V.M.N., I.G., R.K. All authors have read and agreed to the published version of the manuscript.

Funding: This research received no external funding.

Conflicts of Interest: The authors declare no conflict of interest.

\section{References}

1. Matizamhuka, W.R. Spark plasma sintering (SPS)—An advanced sintering technique for structural nanocomposite materials. J. S. Afr. Inst. Min. Metall. 2016, 116, 1171-1180. [CrossRef]

2. Lee, G.; McKittrick, J.; Ivanov, E.; Olevsky, E.A. Densification mechanism and mechanical properties of tungsten powder consolidated by spark plasma sintering. Int. J. Refr. Met. Hard Mater. 2017, 61, 22-29. [CrossRef]

3. Guillon, O.; Gonzalez-Julian, J.; Dargatz, B.; Kessel, T.; Schierning, G.; Rathel, J.J.; Herrmann, M. Field-assisted sintering technology/spark plasma sintering: Mechanisms, Materials, and Technology Developments. Adv. Eng. Mater. 2014, 16, 830-849. [CrossRef]

4. Suárez, M.; Fernández, A.; Menéndez, J.L.; Torrecillas, R.; Kessel, H.U.; Hennicke, J.; Kirchner, R.; Kessel, T. Challenges and opportunities for spark plasma sintering: A key technology for a new generation of materials. Sinter. Appl. 2013, 13, 319-342.

5. Munir, Z.A.; Anselmi-Tamburini, U.M.; Ohyanagi, M. The effect of electric field and pressure on the synthesis and consolidation of materials: A review of the spark plasma sintering method. J. Mater. Sci. 2006, 41, 763-777. [CrossRef]

6. Orrù, R.; Richeri, R.; Locci, A.M.; Cincotti, A.; Cao, G. Consolidation/synthesis of materials by electric current activated/assisted sintering. Mater. Sci. Eng. R 2009, 63, 127-287. [CrossRef]

7. Mamedov, V. Spark plasma sintering as advanced PM sintering method. Powder Metall. 2002, 45, 322-328. [CrossRef]

8. Huang, J.L.; Nayak, P.K. Strengthening alumina ceramic matrix nanocomposites using spark plasma sintering. In Advances in Ceramic Matrix Composites, 2nd ed.; Elsevier Inc.: Amsterdam, The Netherlands, 2018; pp. 231-247. [CrossRef] 
9. Xie, J. Spark Plasma Sintering: A useful technique to develop large-sized bulk metallic glasses. J. Powder Metall. Min. 2013, 2, e109. [CrossRef]

10. Xie, G.Q.; Qin, F.X.; Zhu, S.L. Recent progress in Ti-based metallic glasses for application as biomaterials. Mater. Trans. 2013, 54, 1314-1323. [CrossRef]

11. Mellor, I.; Doughty, G. Novel and emerging routes for titanium powder production-An overview. Key Eng. Mater. 2016, 704, 271-281. [CrossRef]

12. Méar, F.O.; Xie, G.Q.; Louzguine-Luzgin, D.V.; Inoue, A. Spark plasma sintering of Mg-based amorphous ball-milled powders. Mater. Trans. 2009, 50, 588-591.

13. Zheng, B.L.; Ashford, D.; Zhou, Y.Z.; Mathaudhu, S.N.; Delplanque, J.P. Influence of mechanically milled powder and high pressure on spark plasma sintering of Mg-Cu-Gd metallic glasses. Acta Mater. 2013, 6, 4414-4428. [CrossRef]

14. Dudina, D.V.; Bokhonov, B.B.; Olevsky, E.A. Fabrication of porous materials by spark plasma sintering: A review. Materials 2019, 12, 541. [CrossRef] [PubMed]

15. Vincent, N. Spark Plasma Sintering of Titanium and Cobalt Alloys for Biomedical Applications. Ph.D. Thesis, University Trento, Trento, Italy, 2012.

16. Tang, C.F.; Pan, F.; Qu, X.H.; Jia, C.C.; Duan, B.H.; He, X.B. Spark plasma sintering cobalt base superalloy strengthened by Y-Cr-O compound through high-energy milling. J. Mater. Process. Technol. 2008, 204, 111-116. [CrossRef]

17. Gezerman, A.O.; ÇorbacJoLlu, B.D. Effects of Mechanical Alloying on Sintering Behavior of Tungsten Carbide-Cobalt Hard Metal System. Adv. Mater. Sci. Eng. 2017, 2017, 8175034. [CrossRef]

18. Patel, B.; Favaro, G.; Inam, F.; Reece, M.J.; Angadji, A.; Bonfield, W.; Huang, J.; Edirisinghe, M. Cobalt-based orthopaedic alloys: Relationship between forming route, microstructure and tribological performance. Mater. Sci. Eng. C 2012, 32, 1222-1229. [CrossRef]

19. Cavaliere, P.; Sadeghi, B.; Shabani, A. Spark plasma sintering: Process fundamentals. In Spark Plasma Sintering of Materials; Cavaliere, P., Ed.; Springer Nature Switzerland: Cham, Switzerland, 2019. [CrossRef]

20. Song, X.; Liu, X.; Zhang, J. Neck formation and self-adjusting mechanism of neck growth of conducting powders in spark plasma sintering. J. Am. Ceram. Soc. 2006, 89, 494-500. [CrossRef]

21. Oke, S.R.; Ige, O.O.; Falodun, O.E.; Obadele, B.A.; Shongwe, M.B.; Olubambi, P.A. Optimization of process parameters for spark plasma sintering of nano structured SAF 2205 composite. J. Mater. Res. Technol. 2018, 7, 126-134. [CrossRef]

22. Deng, S.; Li, R.; Yuan, T.; Cao, P.; Xie, S. Electromigration-enhanced densification kinetics during spark plasma sintering of tungsten powder. Metall. Mater. Trans. A 2019, 50, 2886-2897. [CrossRef]

23. Knaislová, A.; Novák, P.; Cygan, S.; Jaworska, L.; Cabibbo, M. High-pressure spark plasma sintering (HP SPS): A promising and reliable method for preparing Ti-Al-Si alloys. Materials 2017, 10, 465. [CrossRef]

24. Marek, I.; Vojtěch, D.; Michalcová, A.; Kubatík, T.F. The structure and mechanical properties of high-strength bulk ultrafine-grained Cobalt prepared using high-energy ball milling in combination with spark plasma sintering. Materials 2016, 9, 391. [CrossRef] [PubMed]

25. Kundu, A.; Sittiho, A.; Charit, I.; Jaques, B.; Jiang, C. Development of Fe-9Cr alloy via high-energy ball milling and spark plasma sintering. JOM 2019, 71, 2846-2855. [CrossRef]

26. Coutsouradis, D.; Davin, A.; Lamberigts, M. Cobalt-based superalloys for applications in gas turbines. Mater. Sci. Eng. 1987, 88, 11-19. [CrossRef]

27. Suzuki, A.; Inui, H.; Pollock, T.M. L12-strengthened cobalt-base superalloys. Annu. Rev. Mater. Res. 2015, 45, 345-368. [CrossRef]

28. Aherwar, A.; Singh, A.; Patnaik, A. Cobalt based alloy: A better choice biomaterial for hip implants. Trends Biomater. Artif. Organs 2016, 30, 50-55.

29. Prakasam, M.; Locs, J.; Salma-Ancane, K.; Loca, D.; Largeteau, A.; Berzina-Cimdina, L. Biodegradable materials and metallic implants-A review. J. Funct. Biomater. 2017, 8, 44. [CrossRef]

30. Van Minh, N.; Konyukhov, Y.; Karunakaran, G.; Ryzhonkov, D. Enhancement of densification and sintering behaviour of tungsten material via nano modification and magnetic mixing processed under spark plasma sintering. Metals Mater. Int. 2017, 23, 532-542. [CrossRef]

31. Van Minh, N.; Karunakaran, G.; Konyukhov, Y. Effect of mixing modes and nano additives on the densification and sintering behavior of tungsten material under spark plasma sintering. J. Clust. Sci. 2017, 28, 2157-2165. [CrossRef] 
32. Tiryakioğlu, M.; Dispinar, D.; Uludağ, M.; Yazman, S.; Gemi, L. The effect of 0.5 wt.\% additions of carbon nanotubes \& ceramic nanoparticles on tensile properties of epoxy-matrix composites: A comparative study. Mater. Sci. Nanotechnol. 2017, 1, 15-22.

33. Xing, W.Q.; Yu, X.Y.; Li, H.; Ma, L.; Zuo, W.; Dong, P.; Wang, W.X.; Ding, M. Effect of nano $\mathrm{Al}_{2} \mathrm{O}_{3}$ additions on the interfacial behaviour and mechanical properties of eutectic $\mathrm{Sn}-9 \mathrm{Zn}$ solder on low temperature wetting and soldering of 6061 aluminium alloys. J. Alloys Compd. 2017, 695, 574-582. [CrossRef]

34. Gain, A.K.; Zhang, L. Effects of Ni nanoparticles addition on the microstructure, electrical and mechanical properties of Sn-Ag-Cu alloy. Materialia 2019, 5, 100234. [CrossRef]

35. Gain, A.K.; Zhang, L. Interfacial microstructure, wettability and material properties of nickel (Ni) nanoparticle doped tin-bismuth-silver (Sn-Bi-Ag) solder on copper (Cu) substrate. J. Mater. Sci. Mater. Electron. 2016, 27, 1-13. [CrossRef]

36. Bokhonov, B.B.; Ukhina, A.V.; Dudina, D.V.; Anisimov, A.G.; Mali, V.I.; Batraev, I.S. Carbon uptake during Spark Plasma Sintering: Investigation through the analysis of the carbide "footprint" in a Ni-W alloy. RSC Adv. 2015, 5, 80228-80237. [CrossRef]

37. Fellah, F.; Schoenstein, F.; Dakhlaoui-Omrani, A.; Chérif, S.M.; Dirras, G.; Jouini, N. Nanostructured cobalt powders synthesised by polyol process and consolidated by Spark Plasma Sintering: Microstructure and mechanical properties. Mater. Charact. 2012, 69, 1-8. [CrossRef]

38. Cabibbo, M. Nanostructured cobalt obtained by combining bottom-up and top-down approach. Metals 2018, 8, 962. [CrossRef]

39. Rogal, L.; Kalita, D.; Tarasek, A.; Bobrowski, P.; Czerwinski, F. Effect of SiC nano-particles on microstructure and mechanical properties of the CoCrFeMnNi high entropy alloy. J. Alloys Compd. 2017, 708, 344-352. [CrossRef]

40. Karunakaran, G.; Van Minh, N.; Konyukhov, Y.; Kolesnikov, E.; Venkatesh, M.; Kumar, G.S.; Gusev, A.; Kuznetsov, D. Effect of $\mathrm{Si}, \mathrm{B}, \mathrm{Al}_{2} \mathrm{O}_{3}$ and $\mathrm{ZrO}_{2}$ nano-modifiers on the structural and mechanical properties of $\mathrm{Fe}+0.5 \%$ C alloy. Arch. Civ. Mech. Eng. 2017, 17, 669-676. [CrossRef]

41. Namini, A.B.; Motallebzadeh, A.; Nayebi, B.; Mehdi Shahedi, A.M.; Azadbeh, M. Microstructure-mechanical properties correlation in spark plasma sintered Ti-4.8 wt.\% TiB2 composites. Mater. Chem. Phys. 2018, 223, 789-796. [CrossRef]

(C) 2020 by the authors. Licensee MDPI, Basel, Switzerland. This article is an open access article distributed under the terms and conditions of the Creative Commons Attribution (CC BY) license (http://creativecommons.org/licenses/by/4.0/). 